\title{
PILIHAN BAHASA PADA MASYARAKAT MULTIBAHASA DI DESA BOTOHILISORAKE, NIAS SELATAN (Penelitian Etnografi pada Masyarakat Multibahasawan Nias, Indonesia dan Inggris)
}

\author{
Rebecca Evelyn Laiya \\ Universitas Negeri Jakarta \\ harumiharazaki@gmail.com
}

\begin{abstract}
Abstrak
The aim of this study is to provide a deep understanding of the language choice of a multilingual society. This study is a qualitative research using ethnographic methods. Observation, recording and transcripts and interviews are data collection techniques used. Analysis of the data in this study conducted by transcribing the data recorded in written form, then analyzed and interpreted.

The data analysis showed that: the language choice of Botohilisorake rural communities are very dense, consisting of ten language options. There are three main languages chosen: Nias Selatan dialect, Indonesian and English. But the choice of the most dominant language is Nias Selatan dialect. This is because the villagers who are proud of their identities as a Nias people in general Nias and Nias Selatan people in particular.
\end{abstract}

Keywords: Language choice, multilingual, language teaching

\begin{abstract}
Abstrak
Tujuan dari penelitian ini adalah untuk memberikan pemahaman yang mendalam tentang pilihan bahasa pada masyarakat multibahasa. Penelitian ini adalah penelitian kualitatif yang menggunakan metode etnografis. Observasi, rekaman dan transkrip dan wawancara adalah tehnik pengumpulan data yang digunakan. Analisis data pada penelitian ini dilakukan dengan melakukan transkrip data rekaman ke dalam bentuk tulis, kemudian dianalisis dan dimaknai.

Analisis data menunjukkan bahwa: pilihan bahasa masyarakat desa Botohilisorake sangat lebat, terdiri dari sepuluh pilihan bahasa. Ada tiga bahasa yang paling utama dipilih yaitu bahasa Nias dialek Selatan, bahasa Indonesia dan bahasa Inggris. Tetapi pilihan bahasa yang paling dominan adalah bahasa Nias dialek Selatan. Hal tersebut dikarenakan masyarakat desa bangga akan identitas mereka sebagai orang Nias pada umumnya dan orang Nias Selatan pada khususnya.
\end{abstract}

Kata Kunci: Pilihan bahasa, multibahasa, pengajaran bahasa

PENDAHULUAN

Bahasa tidak akan lepas hubungannya dari masyarakat. Melalui bahasa sebuah masyarakat dapat menunjukkan identitasnya, diantara masyarakat yang lain. Masyarakat Indonesia tentunya adalah masyarakat yang berbeda dengan kelompok sosial atau masyarakat lainnya hal ini dapat terlihat dari bahasa yang dimilikinya. Indonesia adalah negara yang terdiri dari berbagai-bagai pulau dan daerah. Sehingga masyarakat Indonesia memiliki bahasa daerah yang beraneka ragam. 
Untuk mempersatukan keanekaragaman bahasa daerah yang begitu kaya di Indonesia, Indonesia juga memiliki bahasa nasional yaitu Bahasa Indonesia. Selain itu agar Indonesia tetap maju dalam informasi dan teknologi, maka Bahasa Inggris dan juga bahasa asing yang lain diajarkan di sekolah dan dipergunakan oleh masyarakat Indonesia sebagai bahasa asing. Maka dapat dijelaskan bahwa setiap bahasa yang dipergunakan di Indonesia yaitu bahasa daerah, bahasa Indonesia dan bahasa asing memiliki kedudukan yang berbedabeda yang tentunya saling mendukung satu dengan lainnya. Bahkan di beberapa daerah di Indonesia ketiga bahasa tersebut dipakai dalam masyarakatnya. Salah satunya di desa Botohilisorake yang berada di kepulauan Nias, tepatnya di Nias Selatan.

Nias Selatan adalah salah satu daerah yang terletak di bagian selatan pulau Nias. Sekarang ini Nias Selatan sudah melepaskan diri dengan kabupaten induk, yaitu Nias. Berdasarkan UU No. 9 tahun 2003 Nias bagian selatan sekarang telah terbentuk menjadi kabupaten yaitu Kabupaten Nias Selatan (Laiya, 2006:7). Nias Selatan saat ini sudah memiliki 35 kecamatan yang terdiri dari Telukdalam, Onalalu, Kecamatan Fanayama, Luahagudre, Maenamölö, Mazinö, Toma, Lahusa, Simambawa, Suduaöri, Gomo,
Idanötae, Uluidanötae, Börönadu, Umbunasi, Mazö, Susua, Amandraya, Aramö, Őo’u, Onohazumba, Ulususua, Lölöwau, Hilimegai, Lölömatua, Huruna, Ulunoyo, Pulau-Pulau batu, Hibala, Simuk, Pulau-Pulau batu Timur, PulauPulau batu Utara, Pulau-pulau batu Barat, Tana Masa, Hilisalawa'ahe.

Desa Botohilisorake adalah desa yang berada kecamatan Luahagudre. Sejak ditemukannya pantai yang terdapat di desa Botohilisorake (dulu Botohilitanö) sebagai tempat olahraga surfing (selancar air) sejak tahun 1974 ketika kapal pesiar internasional datang ke pantai Sorake (Teluk Lagundri). Kemudian pada tahun 1975 ketika tiga orang surfer (peselancar) yang berkebangsaan Australia yaitu John Troy, Kevin Lovett dan John Gissel menemukan sorake (Teluk Lagundri) sebagai tempat yang memiliki ombak yang 'sempurna' untuk olahraga surfing. Pantai Sorake dipublikasikan di majalah luar negeri dan berlanjut tahun 1978 sampai sekarang (Periplus Action Guide). Latar belakang tersebut yang membuat desa Botohilisorake berkembang menjadi masyarakat penutur multibahasa. Bahasa Nias Selatan sebagai bahasa ibu atau bahasa pertama, kemudian bahasa Indonesia sebagai bahasa kedua atau bahasa nasional, selain itu bahasa Inggris serta bahasa asing lainnya (seperti Jepang, Prancis) menjadi bahasa asing bagi 
masyarakat tersebut untuk menjalin komunikasi dengan wisatawan mancanegara dan sesama masyarakat.

Interaksi di kelas sesungguhnya mencerminkan perilaku berbahasa masyarakat penuturnya. Masyarakat Botohilisorake adalah masyarakat multibahasa yang menggunakan lebih dari dua bahasa antara lain bahasa Nias, bahasa Indonesia dan bahasa Inggris. Situasi kebahasaan tersebut tercermin pada ranah pendidikan di desa Botohilisorake. Pada ranah pendidikan di desa Botohilisorake selain bahasa Indonesia yang dipergunakan terdapat bahasa lain yang dipergunakan yaitu bahasa daerah Nias dialek Utara dan Selatan. Ketiga bahasa tersebut dipergunakan baik di dalam kelas maupun di luar kelas untuk berinteraksi. Baik antara guru dengan murid, antar guru dan antar siswa.Selain itu terdapat juga percampuran bahasa baik di dalam kelas maupun di luar kelas ketika guru dan murid, antar guru dan antar murid ketika berinteraksi. Fenomena pilihan bahasa di desa Botohilisorake sangat menarik. Oleh karena itu peneliti tertarik meneliti sejauh mana pilihan bahasa digunakan pada masyarakat multibahasa di desa Botohilsorake.

Pilihan bahasa adalah bagian dari ilmu sosiolinguistik Fasold menyatakan dalam bukunya bahwa sosiolinguistik dapat menjadi bidang studi karena adanya pilihan pemakaian bahasa (Fasold, 1996:180). Fasold memberikan ilustrasi dengan istilah societal multilingualism (multilingualisme masyarakat) yang mengacu kenyataan adanya banyak bahasa dalam masyarakat (Fasold 1984:180). Tidaklah akan ada bab diglosia, apabila tidak ada variasi tinggi dan rendah. Dengan kata lain tidak akan ada kajian sosiolinguistik tanpa adanya topik pemilihan bahasa. Berdasarkan penelitian yang telah dilakukan (Kartomihardjo, 1981, Fasold, 1984, Hudson, 1996, Wijana 1997) dijelaskan bahwa fenomena pemakaian bahasa atau pemilihan bahasa dalam sebuah masyarakat tutur dikontrol oleh faktorfaktor sosial, budaya dan situasional. Jadi pada akhirnya dalam kajian pemilihan bahasa, para sosiolinguis berusaha memberikan penjelasan hubungan gejala pemilihan bahasa dengan faktor-faktor sosial, budaya dan situasional dalam masyarakat dwibahasa atau multibahasa, baik secara korelasional maupun impilikasional.

Fasold mendefinisikan bahwa pemilihan bahasa adalah sebuah perilaku atau dapat disebut dengan tindakan atau perilaku memakai bahasa terpilih berdasarkan situasi yang berbeda. Pemilihan bahasa bukan sesuatu yang sederhana. Fasold menjelaskan bahwa 
pemilihan bahasa menurut Fasold tidak sesederhana yang kita bayangkan, yakni memilih sebuah bahasa secara keseluruhan (whole language) dalam suatu peristiwa komunikasi (Fasold, 1984:180). Dalam peristiwa komunikasi bahasa, bahasa tidak muncul begitu saja ia berhubungan dengan situasi sosial. Sejalan dengan apa yang jelaskan oleh Labov dan Fanshel dalam situasi sosial sebenarnya seseorang tidak dapat semaunya saja membentuk kalimat (1977:29). Di samping itu Hudson menjelaskan bahwa bahasa tidak dapat digunakan lepas dari konteks dari masyarakat pemakainya (1996:4-5).

Selain situasi atau konteks, yang berhubungan dengan pemilihan bahasa adalah kompetensi. Weinrich menyatakan pilihan bahasa seseorang ditentukan oleh faktor-faktor intralinguistik dan ektralinguistik, salah satu dari faktor intralinguistik adalah kompetensi komunikatif (1953, 3). Ketika seseorang melakukan pemilihan bahasa, artinya ia sedang mengaplikasikan atau menunjukkan performansi komunikatifnya (Much. Khoiri, 2014). Pada dasarnya fenomena pemilihan bahasa ada hubungannya dengan masyarakat dwibahasa atau multibahasa, karena untuk menentukan pilihan bahasa tentunya sudah tersedia pilihan bahasa lain atau ragam lain yang juga digunakan untuk berkomunikasi sehari-hari sebagai pendamping sekaligus pembanding.

Fenomena pilihan bahasa pada masyarakat multibahasa terlihat dalam interaksi murid-murid di dalam kelas, karena interaksi yang terjadi di kelas menggambarkan perilaku berbahasa dalam masyarakat multibahasa. Adapun fenomena pilihan bahasa yang terjadi di kelas meliputi 1) Bahasa Nias dialek Selatan tidak diajarkan di dalam sekolah formal, padahal Nias pada dasarnya memiliki tiga dialek utama yaitu dialek Utara, Selatan dan Tengah. Pembagian dialek ini berdasarkan pembagian daerah di Nias jadi sudah seharusnya setiap daerah yang ada di Nias juga mendapatkan muatan lokal pengajaran bahasa Nias berdasarkan dialek yang dimiliki oleh daerah tersebut tanpa melupakan pengajaran bahasa dialek utara yang merupakan alat komunikasi umum untuk orang Nias. Tetapi pada kenyataannya di desa Botohilisorake yang berada di Nias Selatan tidak mendapatkan pengajaran bahasa Nias dialek Selatan, alasannya belum adanya buku teks yang dapat dipergunakan untuk mengajarkan bahasa Nias dialek Selatan 2) siswa-siswa Sekolah Dasar yang berada di desa Botohilisorake memiliki kesulitan dalam membaca dan menulis. Hal ini menjadi permasalahan yang tersendiri dalam pengajaran di sekolah pada umumnya. 
Permasalahan ini terjadi berdasarkan observasi peneliti yaitu terlalu cepat mereka harus menggunakan bahasa Indonesia dalam membaca dan menulis. Mereka tidak memiliki masa transisi untuk berpindah dari pemahaman mereka dalam bahasa daerah ke bahasa Indonesia. Karena pada umumnya siswa-siswa di sana bahasa pertama mereka atau bahasa ibu mereka adalah bahasa daerah pada umumnya bahasa Nias dialek Selatan. Mereka tidak pernah mempelajari bahasa Nias dialek selatan secara formal yang sesungguhnya membantu mereka belajar menulis dan membaca lalu tiba-tiba harus mempelajari bahasa Indonesia yang asing bagi mereka. Sehingga kemampuan mereka dalam membaca dan menulis lambat pada umumnya. 3) Pada umumnya bahasa Indonesia yang dipergunakan siswa-siswi baik di dalam kelas maupun di luar kelas adalah bahasa Indonesia yang mengalami pengaruh dari bahasa daerah baik dalam kalimat maupun dalam intonasinya. Tidak hanya siswa-siswanya yang menggunakan bahasa Indonesia seperti itu tetapi guru-gurunya dalam mengajar siswa-siswa mereka. 4) Di sekolah dasar sayang sekali tidak lagi diajarkan sebagai mata pelajaran, karena kurikulum untuk SD tidak lagi diajarkan bahasa Inggris. Padahal banyak dari siswa-siswa memiliki kemampuan menggunakan bahasa Inggris meski bahasa Inggris mereka adalah bahasa Inggris informal karena mereka mempelajari bukan dari bangku sekolah melainkan dari interaksi mereka dengan turis asing yang biasanya berkunjung ke desa Botohilisorake pada umumnya adalah turis yang berasal dari Australia. Ini adalah sebuah kelebihan yang seharusnya diasah lebih lagi di bangku sekolah.5) Kebanyakan mahasiswa yang berasal dari desa Botohilisorake ada yang mengambil jurusan pendidikan Bahasa Inggris mengalami kesulitan dalam mempelajari bahasa Inggris karena mereka biasanya memperoleh kemampuan berbahasa Inggris dari pantai secara informal dari para turis asing. Sehingga pada umumnya tata bahasa dan pelafalan mereka menjadi masalah dalam pembelajaran bahasa Inggris pada pendidikan formal. Ditambah mereka tidak mau memperbaiki masalah-masalah pemahaman bahasa Inggris di bangku kuliah mereka.

Berdasarkan latar belakang dan pemaparan teori yang telah dijelaskan di atas, maka peneliti ingin melakukan penelitian yang mendalam dan komprehensif, yaitu dengan menemukan, mendeskripsikan, menganalisis, dan menelaah berdasarkan teori yang relevan dan hasil penelitian terdahulu tentang pilihan bahasa pada masyarakat multibahasa di desa Botohilisorake 
Kabupaten Nias Selatan Provinsi Sumatra Utara. Penelitian diharapkan dapat memberikan pengembangan ilmu sosiolinguistik tentang pilihan bahasa pada masyarakat multibahasa. Serta diharapkan menjadi dasar untuk pengembangan pengajaran bahasa baik bahasa daerah, bahasa Indonesia dan bahasa Inggris berdasarkan kearifan lokal.

Adapun tujuan dari penelitian ini adalah untuk memberikan pemahaman yang mendalam tentang pilihan bahasa masyarakat multibahasa di desa Botohilisorake.

\section{METODE}

Peneliti menggunakan pendekatan kualitatif dengan metode etnografi dalam penelitian ini. Menurut Licoln dan Guba penelitian kualitatif membuka peluang lebih besar hubungan langsung antara peneliti dan responden atau sasaran penelitian. Dengan demikian akan mudah memaknai fenomena yang dideskripsikan dibandingkan istilah tersebut hanya didasarkan kepada pandangan peneliti sendiri (1993, 19). Creswell menjelaskan bahwa penelitian etnografi menerangkan, menganilisis, dan menginterpretasikan pola tingkah laku, kepercayaan, bahasa dan budaya dalam suatu masyarakat $(2008,17)$.

Peneliti melakukan pengumpulan data berdasarkan apa yang dikemukakan
Saville-Troike yaitu 1) observasi 2) partsipasi observasi 3) wawancara sambil lalu, 4) wawancara terfokus tanpa struktur dan 5) perekaman. Analisis data yang dilakukan dengan menggunakan teori Dell Hymes tentang analisis komunikasi. Tetapi analisis komunikasi yang dipergunakan dikaitkan dengan analisis sosiolinguistik. Ketika seseorang menggunakan bahasa terikat oleh siapa dan kepada siapa ia berbicara, kapan dilaksanakan komunikasi, dimana terjadi komunikasi, apa saluran komunikasi tersebut, apa tujuan dari komunikasi tersebut. Jadi yang dilakukan adalah menganalisis pilihan bahasa pada masyarakat multibahasa di desa Botohilisorake berdasarkan komponenkomponen analisis pada tabel di bawah ini

Tabel 1

Analisis Data

\begin{tabular}{|l|l|}
\hline No & \multicolumn{1}{|c|}{ Komponen Analisis } \\
\hline 1 & $\begin{array}{l}\text { Oleh Siapa dan kepada siapa } \\
\text { komunikasi terjadi }\end{array}$ \\
\hline 2 & Kapan terjadi komunikasi tersebut \\
\hline 3 & $\begin{array}{l}\text { Dimana terjadi komunikasi } \\
\text { tersebut }\end{array}$ \\
\hline 4 & $\begin{array}{l}\text { Apa saluran dari komunikasi } \\
\text { tersebut }\end{array}$ \\
\hline 5 & $\begin{array}{l}\text { Apa tujuan dari komunikasi } \\
\text { tersebut }\end{array}$ \\
\hline
\end{tabular}
Adapun tahap-tahap yang dilakukan adalah 1) setelah proses identifikasi, pengkodean dan pengelompokan data mentah, maka apekaspek pilihan bahasa dihubungkan dengan penuturnya 2) melakukan evaluasi ulang 
terhadap data untuk mengetahui pilihan bahasa pada masyarakat multibahasa desa Botohilisorake berdasarkan komponenkomponen analisis 3) menganalisis aspek pilihan bahasa berdasarkan teori ranah fishman 4) Menginterpertasi data dan 5) memaknai pilihan bahasa masyarakat multibahasa desa Botohilisorake dari aspek budayanya.

\section{HASIL}

Berdasarkan analisis maka
didapatkan hasil pilihan bahasa
masyarakat desa Botohilisorake adalah:

Pertama, pilihan bahasa berdasarkan ranah. Berdasarkan hasil penelitian terdapat 7 ranah penggunaan bahasa yaitu terdiri dari (1)ranah keluarga (2)ranah ketetanggaan (3)ranah pertemanan (4)ranah pekerjaan (5)ranah adat (6)ranah agama (7)ranah pendidikan. Pada ranah keluarga terdapat lima pilihan bahasa. Pada ranah ketetanggaan terdapat delapan pilihan bahasa. Sedangkan pada ranah pertemanan terdapat sembilan pilihan bahasa. Sementara pada ranah pekerjaan ada delapan pilhan bahasa. Pada ranah adat terdapat satu pilihan bahasa. Lalu pada ranah agama terdapat tiga pilihan bahasa, dan yang terakhir pada ranah pendidikan terdapat tiga pilihan bahasa. Kedua, pilihan bahasa berdasarkan interaksi. Pilihan bahasa berdasarkan interaksi dalam ranah keluarga beraneka ragam tergantung dari asal dari ayah dan ibu. Peneliti membagi dua kategori asal. Kategori yang pertama apabila ayah dan ibunya memiliki asal yang sama dan kategori kedua ketika ayah dan ibunya berasal dari asal yang berbeda. Orang tua yang asalnya sama berasal dari Botohilisorake dan Gunungsitoli. Orang tua yang berasal dari Botohilisorake tentunya lebih memilih pilihan bahasa Nias dialek Selatan. Sementara orang tua yang asalnya berasal dari Gunungsitoli memilih pilihan bahasa Nias dialek utara. orang tua yang asalnya berbeda pilihan bahasanya pun beranekaragam. Pada ranah ketetanggaan pilihan bahasa yang menjadi sangat berpilihan dan semakin lebat pemakaiannya. Pilihan bahasa dalam interaksi antar orang-orang yang memiliki asal yang sama berjumlah lima yaitu bahasa Nias dialek Selatan, bahasa Nias dialek Utara, bahasa Nias campuran, bahasa Indonesia dan bahasa Batak. Ada empat pilihan bahasa yang dipilih oleh orang-orang yang memiliki asal yang berbeda yaitu pilihan bahasa Nias dialek Selatan dan Utara, bahasa Nias campuran dan bahasa Nias dialek Selatan, bahasa Nias campuran dan bahasa Nias dialek Utara, dan bahasa Indonesia. Pada ranah pertemanan ini peneliti tetap membagi interaksi yang terjadi di dalamnya berdasarkan dua kategori yaitu interaksi pertemanan antar orang yang sama 
asalnya dan interaksi pertemanan antar orang yang asalnya berbeda meski mereka sama-sama tinggal di desa Botohilisorake. Dalam interaksi pertemanan yang asalnya sama terdapat enam pilihan bahasa yang muncul yaitu pilihan bahasa Nias dialek Selatan, Bahasa Nias dialek Utara, bahasa Nias campuran, bahasa Indonesia, bahasa Batak dan bahasa Inggris. Dalam interaksi antar orang yang asalnya berbeda ada tujuh yang menjadi pilihan bahasa mereka yaitu pilihan bahasa Nias dialek Selatan, bahasa Nias dialek Selatan dan Utara, bahasa Nias campuran dan bahasa Nias dialek Utara, bahasa Indonesia dan bahasa Inggris. Dalam interaksi ranah pekerjaaan peneliti kembali membagi dua kategori yaitu (1) kategori asal sama dan (2) kategori asal berbeda. Pilihan bahasa antar sesama orang lokal terdiri dari pilihan bahasa Nias dialek Selatan, bahasa Nias dialek Utara, Bahasa Nias dialek Selatan dan dialek Utara, bahasa Batak. Pilihan bahasa antar orang lokal yang berbeda asalnya adalah pilihan bahasa Nias dialek Selatan dan dialek Utara, bahasa Nias campuran dan bahasa Nias dialek Nias Selatan, bahasa Nias dialek Selatan dan bahasa Indonesia. Pilihan bahasa antar orang lokal dengan turis lokal dari luar desa Botohilisorake ada pilihan bahasa Nias dialek Selatan, bahasa Nias dialek Selatan dan dialek Utara, bahasa Indonesia dan bahasa
Inggris. Pada ranah adat interaksi yang terjadi tidak banyak hanya satu yaitu interaksi antara perangkat desa yaitu kepala desa, sekretaris desa, dan seluruh perangkat desa yang terkait dengan tokohtokoh adat. Maka pilihan bahasa yang dipilih hanyalah satu yaitu bahasa Nias dialek Selatan. Pada ranah agama terdapat dua setting yaitu setting Masjid dan Gereja. Pada Masjid bahasa yang digunakan adalah bahasa Arab dan bahasa Indonesia. Dalam Gereja pilihan bahasa dipergunakan adalah bahasa Nias dialek Selatan dan dialek Utara dan bahasa Indonesia. Dalam ranah pendidikan terbagi atas dua kategori yaitu interaksi di dalam kelas dan interaksi di luar kelas. Di dalam kelas pilihan bahasanya terdiri dari bahasa Nias dialek Selatan, bahasa Nias dialek Utara dan bahasa Indonesia. Sedangkan di luar kelas pilihan bahasa yang dipergunakan meliputi bahasa Nias dialek Selatan, bahasa Nias dialek Selatan dan Utara serta bahasa Indonesia. Ketiga pilihan bahasa dalam bentuk ragam keformalan (situasi). Pada ranah keluarga semua pilihan bahasa yang digunakan dalam ragam akrab (intimate). Pada ranah ketetanggaan semua pilihan bahasa dalam bentuk ragam santai (casual). Pada ranah pertemanan semua pilihan bahasa yang digunakan dalam dua bentuk yaitu ragam santai (intimate) dan ragam santai (casual). Pada ranah pekerjaan semua 
pilihan bahasa dipergunakan dalam bentuk ragam usaha (consultative). Pada ranah adat semua bahasa yang dipergunakan dalam bentuk ragam resmi (formal). Pada ranah agama semua bahasa yang dipergunakan dalam bentuk ragam beku (frozen). Pada ranah pendidikan semua bahasa yang dipilih dalam bentuk ragam resmi (formal) dan dalam bentuk ragam santai (casual).

\section{PEMBAHASAN}

Berdasarkan analisis di atas maka dapat dijelaskan bahwa pilihan bahasa pada masyarakat multibahasa di desa Botohilisorake dapat ditinjau dari tiga sudut pandang yaitu berdasarkan ranah, berdasarkan interaksi dan ragam keformalan (situasi). 1) Pada ranah terlihat jelas seperti apa yang telah diteliti oleh Fishman bahwa pilihan bahasa terjadi dalam ranah-ranah yang berbeda (1972:22). Peneliti menemukan pilihan bahasa muncul pada tujuh ranah pemakaian bahasa. Dalam setiap ranah terdapat pilihan bahasa yang bervariasi. Pilihan bahasa yang paling banyak terdapat pada ranah pertemanan. Hal ini disebabkan karena interaksi di dalam ranah pertemanan begitu banyak sehingga para penutur juga harus memilih pilihan bahasa yang beranekaragam agar dapat mampu berkomunikasi dengan baik dengan penutur yang lain. Sementara itu ranah penggunaan bahasa yang paling sedikit memiliki pilihan bahasa adalah ranah adat. Alasannya karena komunikasi dalam ranah adat ini terjadi dalam interaksi orang-orang yang memiliki latar belakang yang sama yaitu tokoh adat dan tokoh masyarakat dalam bahasa yang resmi daerah Nias dialek selatan. Komunikasi dalam ranah adat ini sudah merupakan budaya turun-temurun masyarakat Nias Selatan pada umumnya dan masyarakat Botohilisorake pada khususnya. Komunikasi dilakukan dengan cara mengadakan rapat adat atau dalam bahasa Nias orahu atau orahua. Bahasa yang dipergunakan adalah bahasa Nias dialek Selatan dan tidak ada pilihan lain. Bagi pendatang atau yang berasal dari daerah lain kemudian tinggal di desa Botohilisorake harus mampu menyesuaikan diri akan situasi ini.

Pilihan-pilihan bahasa yang paling banyak dipilih dalam ranah penggunaan bahasa adalah pilihan bahasa 1) bahasa Nias dialek Selatan 2) pilihan bahasa bahasa Nias dialek Selatan dan Utara 3) dan pilihan bahasa bahasa Indonesia. Hal ini disebabkan karena: bahasa Nias dialek Selatan adalah pilihan bahasa yang paling dominan karena desa Botohilisorake adalah desa yang terdapat dalam kabupaten Nias Selatan. Penduduk yang paling banyak berdomisili di desa Botohilisorake adalah mereka yang 
memiliki latarbelakang berasal dari Nias selatan. Pilihan bahasa yang paling banyak dipilih juga pada ranah penggunaan bahasa adalah pilihan bahasa bahasa Nias dialek Selatan dan bahasa Nias dialek Utara. Adapun alasannya adalah karena penduduk di desa Botohilisorake memiliki latarbelakang yang bervariasi. Selain yang berasal asli dari Botohilisorake yang termasuk dalam kabupaten Nias selatan dan yang menggunakan bahasa Nias dialek selatan. Ada juga yang berasal dari Gunungsitoli dan Sirombu yang merupakan daerah Kotamadya Gunungsitoli atau termasuk Nias utara, yang menggunakan bahasa Nias dialek utara. Apabila pengguna bahasa Nias dialek selatan dan pengguna bahasa Nias dialek utara berkomunikasi. Mereka lebih senang menggunakan bahasa Nias dialek mereka masingmasing. Tujuannya menurut mereka agar tidak ada kesalapahaman dalam berkomunikasi. Bahasa Indonesia sering dipergunakan oleh penduduk desa Botohilisorake yang berasal dari luar daerah Nias dengan sesama penduduk desa Botohilisorake yang asli berasal dari Nias. Apabila mereka tidak terlalu mampu berkomunikasi dalam bahasa Nias. Maka bahasa Indonesia dapat membantu mereka berkomunikasi.

Sementara bahasa yang paling sedikit digunakan oleh penggunanya adalah bahasa Arab. Hal ini dikarenakan karena bahasa Arab hanya dipergunakan oleh penduduk desa Botohilisorake yang beragama Islam dan hanya dipergunakan pada ranah agama yaitu tepatnya di Masjid. Bahasa Arab yang digunakan adalah bahasa Arab yang terdapat pada ayat-ayat Kitab Suci Al-Quran dan bukan bahasa Arab yang dipergunakan untuk berkomunikasi. 2) Berdasarkan interaksi dalam tujuh ranah pemakaian bahasa terdapat dua kategori yaitu interaksi asal yang sama dan interaksi asal yang berbeda. Bagi yang asalnya sama mereka menggunakan bahasa daerah yang sama lalu bagi mereka yang asalnya berbeda mereka menggunakan bahasa daerah yang berbeda tergantung dari asal mereka. Bahasa daerah menjadi pilihan yang asalnya sama karena keakraban lebih terlihat dapat dibangun dan mereka tetap ingin mempertahankan identitas mereka sebagai orang asli desa Botohilisorake. Sementara bagi yang asalnya berbeda bahasa daerah masing-masing menjadi pilihan karena mereka juga ingin membangun keakraban, agar terjalin komunikasi yang saling dimengerti dan mereka juga ingin mempertahankan identitas mereka sebagai pendatang di desa Botohilisorake. Sementara Bahasa Indonesia dan bahasa Inggris dipilih apabila salah satu dari orang yang berkomunikasi tidak mampu 
menggunakan bahasa daerah selain itu dipergunakan untuk bahasa komunikasi untuk pekerjaan. Dan bahasa Arab menjadi satu-satunya bahasa yang dipergunakan di ranah Agama untuk pembacaaan Kitab Suci Al-Quran. 3) Berdasarkan ragam keformalan atau situasi maka dalam setiap ranah ragam keformalan bervariasi. Ragam akrab (intimate) dipilih dalam ranah dimana orang-orang di dalamnya sangat akrab. Bahkan terkadang panggilan yang digunakan seperti ejekan tetapi tidak dinilai dari sudut kesopanan melainkan dari sudut keakraban. Ragam santai (casual) dipilih pada ranah yang di dalamnya terdiri dari orang-orang yang akrab tetapi masih terdapat batasanbatasan tertentu dalam berbicara contohnya dalam ranah pendidikan yaitu interaksi antara guru dan siswa di luar kelas tentunya mereka menggunakan ragam yang santai dan tidak mungkin menggunakan ragam akrab, karena ada batas-batas kesopanan yang harus diperhatikan. Ragam usaha (consultative) dipergunakan dalam ranah dimana orangorang di dalam berinteraksi untuk tujuan pekerjaan. Ragam formal dipergunakan dalam ranah yang formal tetapi tidak dalam situasi terlalu kaku. Dan ragam beku (frozen) dipergunakan dalam ranah dimana komunikasi yang terjadi tidak hanya kepada sesama manusia tetapi lebih mengarah antara Tuhan dan umatnya.

Meskipun demikian penelitian ini masih penuh keterbatasan. Hal ini dikarenakan penelitian ini hanya terbatas dilakukan di salah satu desa di Nias Selatan. Oleh sebab itu penelitian ini hanya terbatas untuk melihat pilihan bahasa yang ada di desa Botohilisorake bukan Nias Selatan secara keseluruhan.

\section{SIMPULAN}

Kesimpulan yang dapat ditarik dalam penelitian ini bahwa pilihan bahasa pada masyarakat multibahasa di desa Botohilisorake sangat beragam dan lebat. Meski demikian bahasa daerah Nias tidaklah ditinggalkan oleh penduduk desa Botohilisorake. Pilihan bahasa yang paling dominan dipilih oleh desa Botohilisorake adalah bahasa Nias dialek Selatan. Hal ini baik, mereka masih mempertahankan identitas mereka sebagai orang Nias dan tetap bangga mempergunakan bahasa daerah mereka sendiri. Walaupun bahasa Indonesia, bahasa Batak, bahasa Inggris dan bahasa Arab juga menjadi pilihan bahasa yang mereka pergunakan.

Pilihan bahasa muncul dapat berdasarkan ranah, interaksi dan situasi keformalan. Di dalam masyarakat multibahasa desa Botohilisorake. Pada dasarnya secara garis besar di dalam masyarakat Botohilisorake terdapat 5 (lima) bahasa yang dipergunakan yaitu (1) 
bahasa Nias (2) bahasa Indonesia (3)

bahasa Batak (4) bahasa Inggris dan (5)

bahasa Arab. Namun berdasarkan analisis terdapat 10 (sepuluh) pilihan bahasa yang dipergunakan untuk berkomunikasi yaitu (1) bahasa Nias dialek selatan (2) bahasa Nias dialek utara (3) bahasa Nias dialek selatan dan dialek utara (4) bahasa Nias campuran (5) bahasa Nias campuran dan bahasa Nias dialek selatan (6) bahasa Nias campuran dan bahasa Nias dialek utara (7) bahasa Indonesia (8) bahasa batak (9) bahasa Inggris dialek Australia (10) bahasa Arab. Di desa Botohilisorake terdapat tujuh ranah pemakaian bahasa yaitu (1) ranah keluarga (2) ranah ketetanggaan (3) ranah pertemanan (4) ranah pekerjaan (5) ranah adat (6) ranah agama dan (7) ranah pendidikan. Pada setiap ranah pilihan bahasa sangat bervariasi dan berbeda-beda antar satu dengan yang lainnya. Di dalam setiap ranah terdapat interaksi. Semakin dekat hubungan antar penutur di desa Botohilisorake maka bahasa yang mereka adalah bahasa daerah, semakin jauh hubungan antar penutur di desa Botohilisorake maka bahasa yang dipakai adalah bahasa Indonesia dan bahasa Inggris. Sementara penggunaan bahasa Arab hanya dipergunakan antar chotib dan umatnya ketika membacakan kitab suci Al-Quran. Dan tidak ada hubungannya dekat dan jauhnya hubungan antara chotib dan umatnya

\section{REFERENSI}

Creswell, John W. Educational Research, Planning, Conducting and Evaluating Quantitative and Qualitative Research. Colombus Ohio: Pearson Merrill Prentice Hall, 2008.

Fasold, Ralph The Sociolinguistics of Society. USA: Basil Blackwell, 1984.

Fishman, Joshua A, The Relationship between micro- and macroSociolinguistics in the study of who speaks what language to whom and when. In John B. Pride and Janet Holmes (eds) Sociolinguistics. Harmondsworth: Penguin, 1972.

Hudson, Richard A, Sosiolinguistik. Second Edition. Cambridge: Cambridge University Press, 1996.

Labov, William dan David Fanshel,

Therapautic Discourse, Psychotherapy as Conversation, New York: Academic Press, 1977.

Laiya, Bamböwö, Nilai Budaya Nias Selatan: Sumane Böwö Ni Orisi (Telukdalam: Yayasan Bamper Madani: 2006.

Sumatra: Nias, A Surf City on Stilts" di Periplus Action Guide, Surfing Indonesia: A Search for the World's Most Perfect Wave Edisi ketiga.

Lincoln, Yvonna S. dan Egon Guba, Naturalistic Inquiry (Beverly Hills: Sage Publications, 1993.

Much. Khoiri, Lebih Akrab dengan Pemilihan

Bahasa,http://m.Kompasiana.com/ post/read/597467/3/lebih-akrabdengan-pemilihan-bahasa.html tanggal 25 Juni 2014.

U. Weinreich. Language in Contact, New York: Press Linguistics Circle of New York, 1953. 
